\title{
SQUAMOUS CELL CARCINOMA OF SCROTUM: A RARE CASE OF SCROTAL NEOPLASM
}

\author{
Shanggar K, Ng CH, Razack AH, Dublin N \\ Department of Surgery, Faculty of Medicine, University of Malaya, Kuala Lumpur, Malaysia.
}

\begin{abstract}
:
Malignant tumours of the scrotum are very rare. Several type of occupations have been identified as high risk for the development of SCC of scrotum e.g paraffin and shale oil workers (1), textile workers (2) etc. We report a rare case of SCC of scrotum. Search of our records in the Urology and Pathology departments of our Centre showed that this is the only case of SCC of the scrotum in the last 10 years. (JUMMEC 2010; 13 (1): 59-62)
\end{abstract}

KEYWORDS: squamous cell carcinoma, scrotum, inguinal lymph node

\section{Introduction}

A 76-year-old gentleman was referred with a history of progressively worsening ulcer on the left side of his scrotum of 6 months duration. He denied any history of trauma to the scrotum and there was no exposure to industrial irritants noted.

Examination revealed a fungating ulcer with everted edges mainly at the left side of scrotum encroaching slightly the base of the penis and to the right side of the median raphe. There was also bilateral fixed and matted inguinal lymphadenopathy.

His laboratory tests were within normal limits. Wedge biopsy of the lesion showed a moderately differentiated SCC. A computed tomography (CT) imaging scan and a Magnetic Resonance Imaging (MRI) for staging revealed a well localized lesion in the scrotum with bilateral inguinal lymphadenopathy and with no evidence of other distant metastasis (Figure 1).

The patient was subjected to a wide local excision of the tumour with scrotal skin flap reconstruction. Histopathology revealed a well-differentiated SCC with no lymphovascular permeation and surgical margins were noted to be free of tumour. He then underwent and completed three cycles of chemotherapy with carboplatin and 5-Fluorouracil (5-FU) regime in view of the matted bilateral inguinal lymphadenopathy. Post Chemotherapy, he underwent bilateral radical inguinal lymphadenectomy for the persistent lymphadenopathy and the histopathology confirmed no spread to the lymph nodes (10 and 28 lymph nodes on the right and left respectively) except for the skin nodule overlying the left nodes.

This gentleman has not presented with any evidence of recurrence or metastasis in the last two years of followup, both clinically and on imaging.

\section{Discussion}

Malignant tumour of the scrotum is a very rare condition worldwide. The SCC of the scrotum is the commonest of the various neoplasm of the scrotum like Basal Cell Carcinoma, Malignant Melanoma and Paget's disease (3). The incidence of this disease is only about 0.2 to 0.3 cases per 100,000 men above the age of 35 years (4). Age of patients presenting with SCC of scrotum usually ranges from 50 to 60 years old (5).

As in most cutaneous lesions, they usually seek medical advice about 12 months after the onset of the ulcer because of extensive usage of topical treatment (6). This delay could lead to a more advanced stage at the time of diagnosis.
Correspondence:
Shanggar Kuppusamy
Department of Surgery
Faculty of Medicine
University of Malaya
50603 Kuala Lumpur, Malaysia
E-mail: drshanggar@um.edu.my 


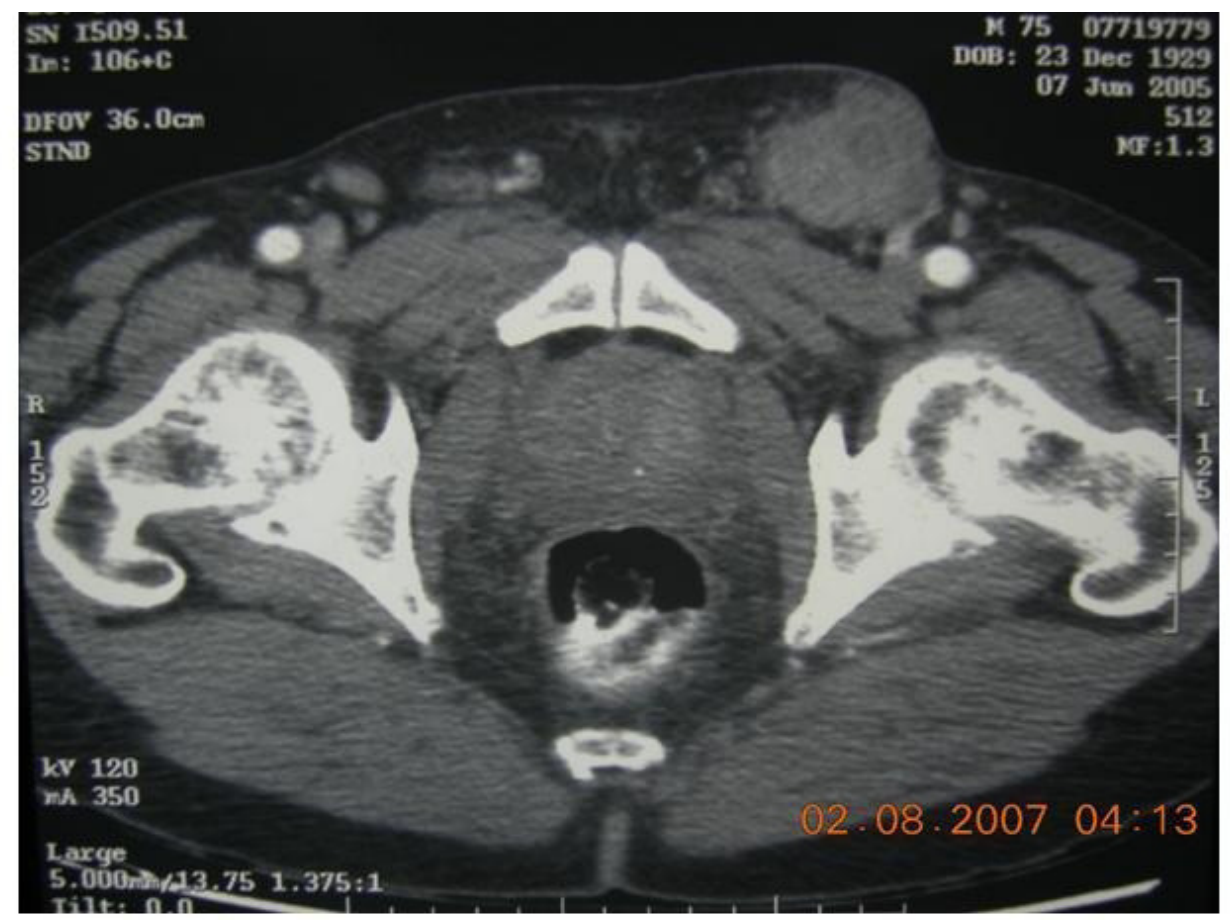

Figure 1: CT scan showing enlarged Bilateral Inguinal lymph nodes

Ipsilateral inguinal lymphadenopathy is usually noted in about $40 \%$ to $50 \%$ of patients and only half of them i.e $25 \%$ have proven metastasis to the lymph nodes (6).

Staging of the disease can be done with CT scan, although it is not a reliable modality to differentiate between inflammatory and metastatic lymph nodes (3). MRI is rapidly emerging as a reliable tool for this purpose (7). Currently used staging system for SCC of the scrotum is shown in Table 1.

Figure 1: Staging system for Scrotal Carcinoma (6)

\begin{tabular}{|c|l|}
\hline Stage & Description \\
\hline A1 & Localised to scrotal wall \\
\hline A2 & $\begin{array}{l}\text { Locally extensive tumour invading adjacent } \\
\text { structures (testis, spermatic cord, penis, pubis, } \\
\text { perineum) }\end{array}$ \\
\hline B & $\begin{array}{l}\text { Metastaticdisease involving inguinal luph nodes } \\
\text { only }\end{array}$ \\
\hline C & $\begin{array}{l}\text { Metastatic disease involving pelvic lymph nodes } \\
\text { without evidence of distant spread }\end{array}$ \\
\hline D & $\begin{array}{l}\text { Metastatic disease beyond the pelvic lymph } \\
\text { nodes involving distant organs }\end{array}$ \\
\hline
\end{tabular}

Upon confirmation of the diagnosis by biopsy of the scrotal lesion, the treatment of choice is a wide local excision with a margin of $2 \mathrm{~cm}$ and the defect is closed primarily or with split-thickness skingrafting if necessary (3). Lymph node management is controversialunilateral versus bilateral lymphadenectomy and the timing of lymphadenectomy (prophylactic versus delayed). The need for radical inguinal lymph node dissection is debatable as only $25 \%$ of cases show evidence of metastasis as compared to the morbidity of the procedure. Therefore, it is recommended that lymph node dissection be undertaken in cases with proven metastasis i.e Sentinel node biopsy positive (3). Sentinel biopsy as described by Cabanas in 1977 (8) for penile cancer is no more recommended due to high false negative rates (25\%, range $9-50 \%$ ) (9). Similarly, we feel that sentinel biopsy for scrotal squamous cell carcinoma should not be done and a better alternative would be a modified radical inguinal lymphadenectomy. Our patient was noted to present with bilateral fixed and matted inguinal lymphadenopathy which would have complicated any attempt of an inguinal lymph node dissection. Therefore, a course of chemotherapy was given. Clinical improvement of the lymph node status was noted but in view of the persistence, it was then decided that the patient should undergo a left radical 


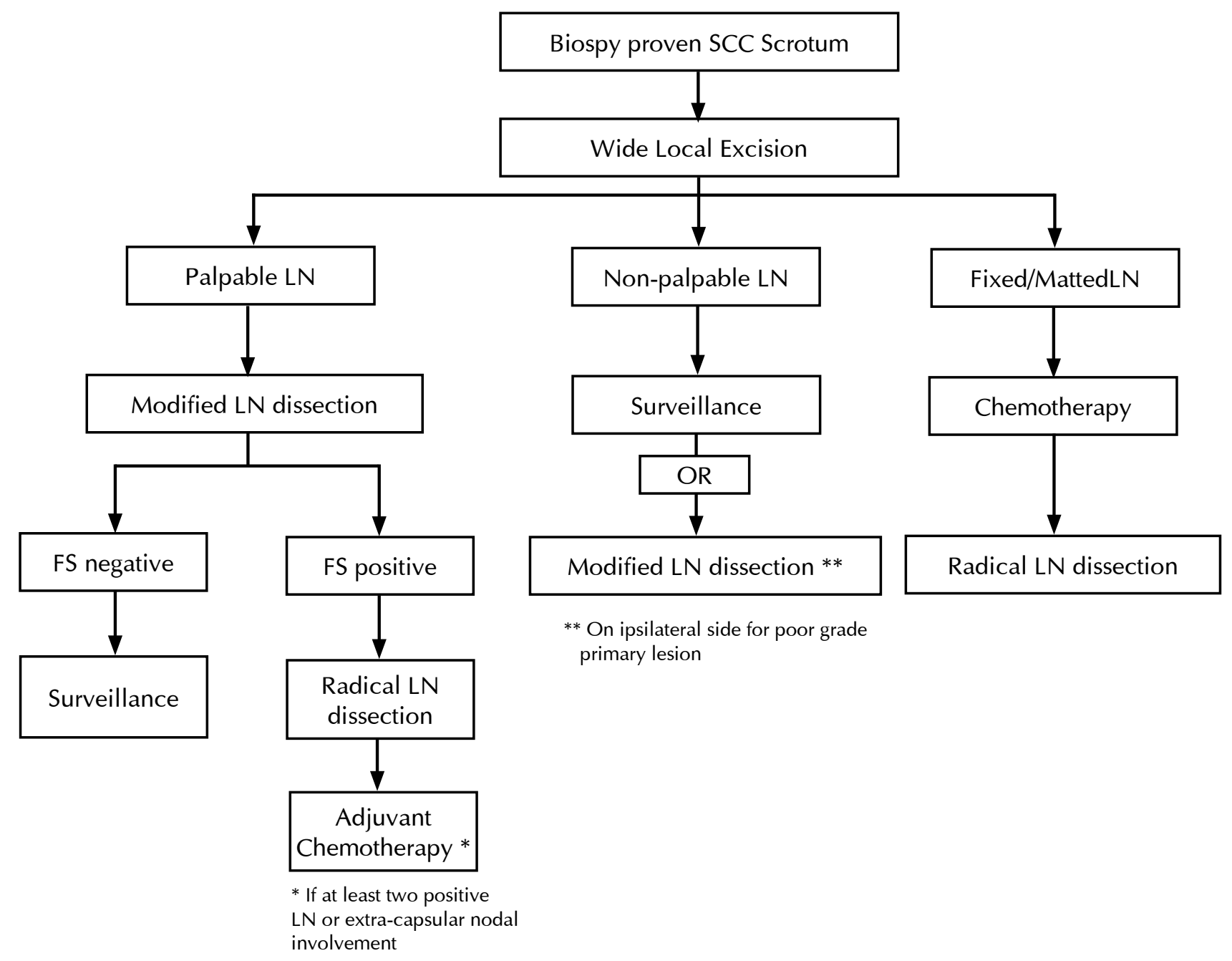

Figure 2: Algorithm for management for biospy proven SCC

FS - Frozen section; LN - Lymph node

lymphadenectomy plus a right modified inguinal lymphadenectomy. To the patient's advantage, it was found in the histopathology that the lymph nodes had no evidence of metastasis and the operation itself was less morbid. Therefore, we propose the following algorithm (Figure 2) be used in the management of biopsy proven SCC of scrotum.

Radiation therapy is not effective in this condition and is reserved only for those with incomplete surgical resection and in patients who are unfit to undergo surgery (10). Chemotherapy has been reported to be quite successful in preventing the spread and recurrence of the disease. Reports showed good success in a couple of patients using bleomycin. However, these patients had low grade disease (11). Combination therapy of methotrexate, bleomycin and cisplatin achieved a $72 \%$ response rate in patients who had inoperable or metastatic squamous cell carcinoma of the male genital tract (12). Successful treatment was also reported by Hussein et al and Fisher et al by using a combination of Cisplatin and 5 Fluorouracil (13 \& 14). Although, the number of patients was small i.e 29, those treated with neo-adjuvant Cisplatin and 5-Fluorouracil for fixed or recurrent nodal disease for penile cancer showed good response $(66 \%)$ and in $38 \%$ of them, resection could be performed (14). Carboplatin was used in our patient because of the possible toxicity of Cisplatin in geriatric patients. Randomized multicenter trials are needed to determine the role of chemotherapy in the management of scrotal SCC. 
Prognosis of this condition is poor with many series reporting death within 2 years of diagnosis; however, the prognosis is related to the stage of the disease as reported by Ray and Whitmore (6). Stage A1 has a survival rate of more than $75 \%$, Stage B only $44 \%$, whereas, Stage $C$ \& D has very minimal chance of survival (3 \& 15).

\section{Conclusion}

SCC of the scrotum is a rare but aggressive condition. The best prognosis for this disease is achievable if diagnosed in early stage where a wide local excision with or without radical inguinal lymph node dissection and adjuvant chemotherapy could be administered.

\section{References}

1. Graves RC, Flo S. Carcinoma of the scrotum. J Urol 1940 43: 309.

2. Castiglione FM Jr, Selikowitz SM, Dimond RL. Mule spinner's disease. Arch Dermatol 1985; 121: 370.

3. Lowe FC. Squamous-Cell Carcinoma of the Scrotum. Urologic Clinics of North America 1992; 19: 263-65.

4. Lowe FC. Squamous-Cell Carcinoma of the Scrotum. J Urol 1983; 130: 423.

5. Kickham, CJE, Dufresne, M. An assessment of carcinoma of the scrotum. J Urol 1967; 98: 108.

6. Ray B, Whitmore Jr WF. Experience with carcinoma of the scrotum. J Urol 1977; 177: 741-745.

7. Muglia V, Tucci S, et al. Magnetic resonance imaging of scrotal diseases: when it makes the difference, Adult Urology 2002; 59; 419-423.
8. Cabanas RM. An approach for the treatment of penile carcinoma. Cancer 1977; 39:456-466.

9. Pettaway CA, et al. Sentinel lymph node dissection for penile carcinoma: the M.D. Anderson Cancer Center Experience. J Urol 1995; 154: 1999-2003.

10. McDonald MW. Carcinoma of scrotum. Urology 1982; 19: 269.

11. Ichikawa T, Nakano I, Hirokawa I. Bleomycin treatment of the tumours of penis and scrotum. $J$ Urol 1969; 102: 699.

12. Dexeus FH, Logothetis CJ, Sella A., et al. Combination Chemotherapy with Methotrexate, Bleomycin and Cisplatin for Advanced Squamous Cell Carcinoma of the Male Genital Tract. J Urol 1991; 146: 12841287.

13. Hussein, AM, Benedetto, P. and Sridhar, K.S.: Chemotherapy with Cisplatin and 5-fluorouracil for penile and urethral squamous cell carcinomas. Cancer 1990; 65: 433.

14. Fisher, HAG, Barada JH, Horton, J, Von Roemeling, R. Neoadjuvant therapy with Cisplatin and 5-fluorouracil for stage III squamous cell carcinoma of the penis. J Urol, part 2, 143: 352A, abstract $653,1990$.

15. Andrews PE, Farrow GM, Oesterling JE: Squamous cell carcinoma of the scrotum: Long-term followup of 14 patients. J Urol 1991; 146: 1299. 